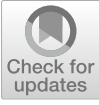

Cite as

Nano-Micro Lett.

(2020) 12:158

Received: 11 July 2020

Accepted: 22 July 2020

Published online: 7 August 2020

(C) The Author(s) 2020

\section{Suppressing Li Dendrites via Electrolyte Engineering by Crown Ethers for Lithium Metal Batteries}

\author{
Shanqing Zhang ${ }^{1}$ \\ $\bowtie$ Shanqing Zhang, s.zhang@griffith.edu.au \\ 1 Centre for Clean Environment and Energy, School of Environment and Science, Gold Coast Campus, \\ Griffith University, Southport, QLD 4222, Australia
}

\begin{abstract}
Electrolyte engineering is considered as an effective strategy to establish stable solid electrolyte interface (SEI), and thus to suppress the growth of lithium dendrites. In a recent study reported in Advanced Functional Materials by Ma group, discovered that strong coordination force could be founded between 15-Crown-5 ether (15-C-5) and Li+, which facilitates the crown ether (15-C-1) to participate in the solvation structure of $\mathrm{Li}+$ in the electrolyte for the same purpose. Such a novel strategy might impact the design of highperformance and safe lithium metal batteries (LMBs).
\end{abstract}

KEYWORDS Li dendrites; Crown ethers; Lithium metal batteries; Electrolyte

Electrolyte engineering is considered as an effective strategy to establish stable solid electrolyte interphase (SEI) and thus to suppress the growth of lithium dendrites. A recent study reported in Advanced Functional Materials by Ma' group, discovered that strong coordination force could be founded between 15-Crown-5 ether (15-C-5) and $\mathrm{Li}^{+}$, which facilitate the crown ether (15-C-1) to participate in the solvation structure of $\mathrm{Li}^{+}$in the electrolyte for the same purpose. Such a novel strategy might impact the design of high-performance and safe lithium metal batteries (LMBs) [1].

LMBs have attracted escalating attention due to the ultrahigh theoretical capacity, which is ten times of lithium-ion batteries (LIBs). However, the potential safety issue of LMBs is throttling the application due to the significant volume change and uncontrolled dendrites growth of lithium (Li) dendrites [2-4]. Due to the super reactivity, the parasitic reaction between Li metal and electrolyte will react quickly to form the SEI film. However, the fragile and uneven SEI film is easily broken, leading to malignant dendritic growth and electrolyte consumption. To solve this problem, some functional additives that could coordinate with $\mathrm{Li}^{+}$are introduced in liquid electrolytes, which are beneficial to the construction of stable SEI film [5]. The competitive combination behavior between the electrolytes and the additives with $\mathrm{Li}^{+}$will determine the migration and deposition of $\mathrm{Li}^{+}$ or $\mathrm{Li}^{+}$clusters [6].

In Ma's work in Advanced Functional Materials, the mechanism of the strong coordination between 15-Crown-5 ether (15-C-5) and $\mathrm{Li}^{+}$is used to inhibit the uneven growth of Li dendrites as illustrated in Fig. 1 [1]. As demonstrated by the charge density simulation, the $\mathrm{Li}^{+}$lies in the center of 12-C-4 and 15-C-5 to form four or five Li-O bonds, respectively (Fig. 2a, b), but $\mathrm{Li}^{+}$lies on one side of $18-\mathrm{C}-6$ and to form only four $\mathrm{Li}-\mathrm{O}$ bonds (Fig. 2c). So, 15-C-5 possessed the strongest combination ability to participate in the solvation of $\mathrm{Li}^{+}$. Because of this, the $\mathrm{Li}^{+} / 15-\mathrm{C}-5$ complex could aggregate and distribute evenly at the Li metal surface due to the electrostatic adsorption, building up a protective layer to reduce the contact between electrolyte solvent and Li metal. Fortunately, the LiF is not affected in this process; in fact, $\mathrm{LiF}$ is the highest content component in SEI film (Fig. 2d). In addition, due to the existence of $\mathrm{Li}^{+} / 15-\mathrm{C}-5$ protective layer, $\mathrm{Li}^{+}$is distributed uniformly on the Li metal surface, which facilitates the formation of the smooth and dense SEI film and drives uniform Li deposition (Fig. 2e). As a result, the crown ether 15-C-5 is beneficial to the long-term performance of Li symmetric battery with 170 cycles, which is twice of that in the blank electrolyte (Fig. 2f). The most 


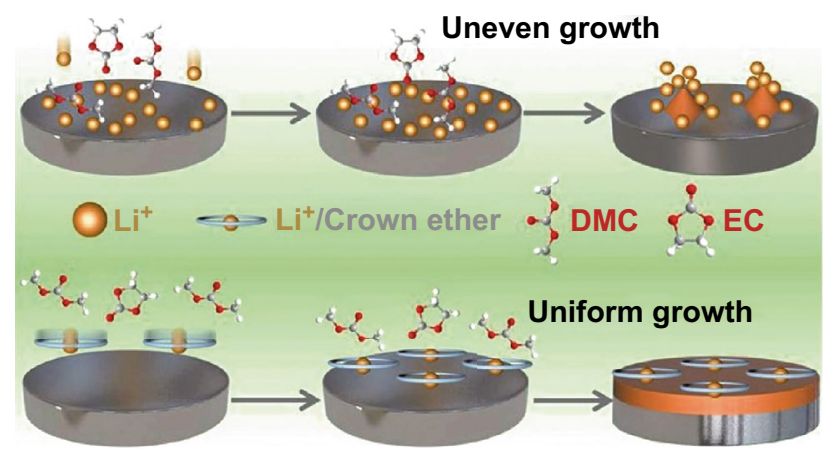

Fig. 1 Illustrative schemes of the growth of $\mathrm{Li}$ dendrites in a black electrolyte and b crown ether-contained electrolyte. Adapted with permission from Ref. [1] significant contribution of this work by Ma group is that it theoretically and experimentally demonstrates the proposed electrolyte additive helps the formation of superior SEI film through taking part in the processes of the solvation of $\mathrm{Li}^{+}$, the nucleation and growth of Li dendrites.

In summary, Ma and coworkers demonstrate that electrolyte engineering is an effective strategy to establish SEI film to suppress dendrite growth in LMBs, and the crown ether 15-C-5 is a novel and promising electrolyte additive for high-performance and safe LMBs. (a)

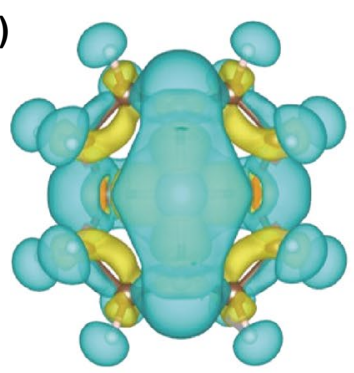

(d)

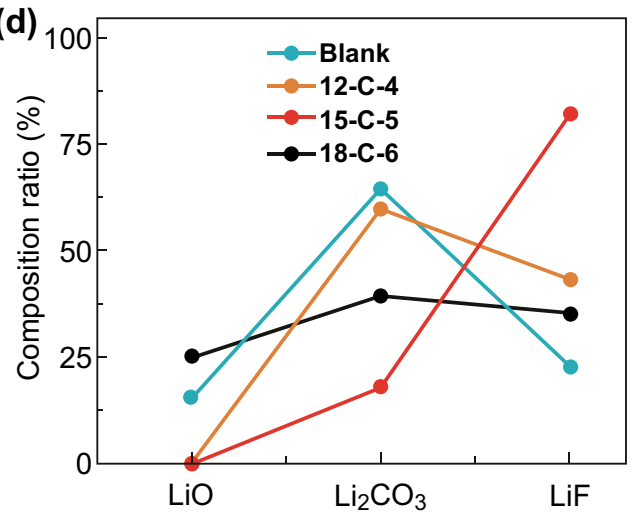

(b)

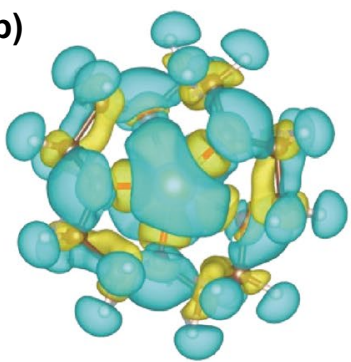

(e)

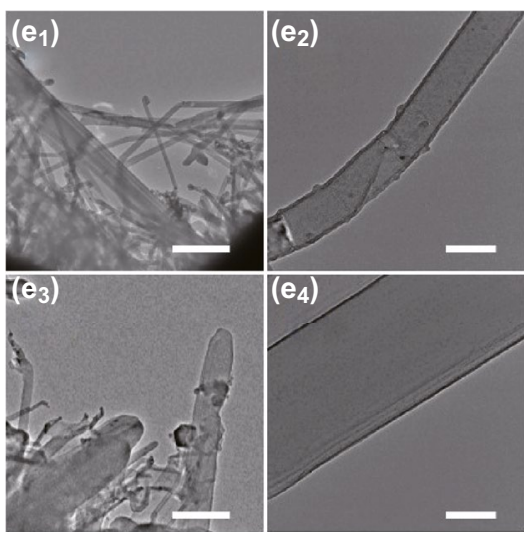

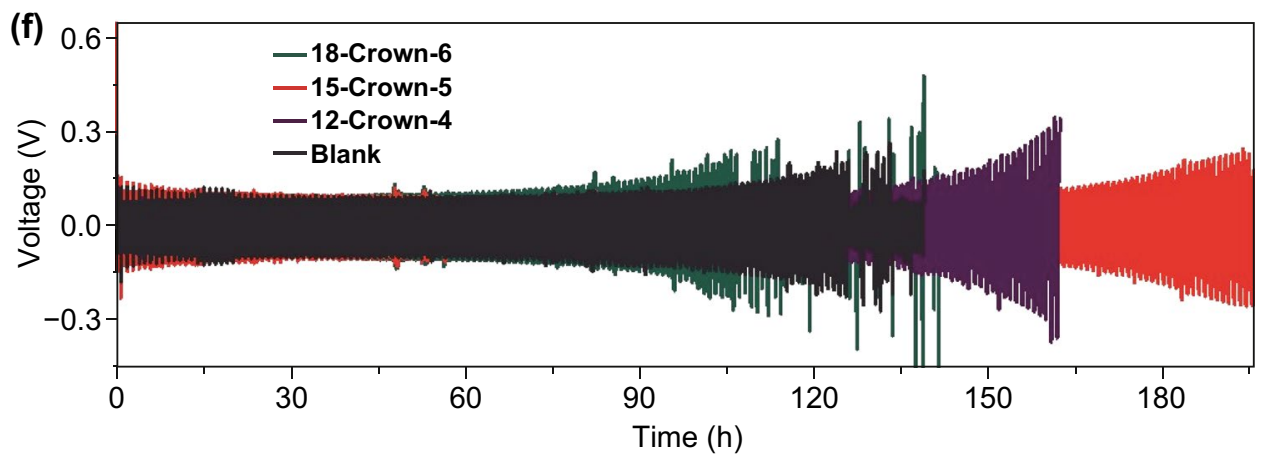

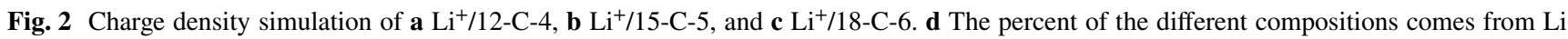
$1 \mathrm{~s}$ XPS spectra. e The cryo-electron microscopy (cryo-EM) of metal dendrites in blank electrolyte $\left(\mathrm{e}_{1} \& \mathrm{e}_{2}\right)$ and $2.0 \mathrm{wt} \% 15-\mathrm{C}-5 \mathrm{contained}$ electrolyte $\left(\mathrm{e}_{3} \& \mathrm{e}_{4}\right.$ ) (scale bars: $2 \mu \mathrm{m}$ and $200 \mathrm{~nm}$ for $\mathrm{e}_{1} \& \mathrm{e}_{3}$ and $\mathrm{e}_{2} \& \mathrm{e}_{4}$, respectively). f Electrochemical behavior of symmetric cell in the blank electrolyte and $2.0 \mathrm{wt} \%$ 12-crown-4 (12-C-4), $2.0 \mathrm{wt} \%$ 15-C-5, 18-crown-6 (18-C-6) contained electrolyte. Adapted with permission from Ref. [1] 
Open Access This article is licensed under a Creative Commons Attribution 4.0 International License, which permits use, sharing, adaptation, distribution and reproduction in any medium or format, as long as you give appropriate credit to the original author(s) and the source, provide a link to the Creative Commons licence, and indicate if changes were made. The images or other third party material in this article are included in the article's Creative Commons licence, unless indicated otherwise in a credit line to the material. If material is not included in the article's Creative Commons licence and your intended use is not permitted by statutory regulation or exceeds the permitted use, you will need to obtain permission directly from the copyright holder. To view a copy of this licence, visit http://creativecommons.org/licenses/by/4.0/.

\section{References}

1. H. Wang, J. He, J. Liu, S. Qi, M. Wu et al., Electrolytes enriched by crown ethers for lithium metal batteries. Adv. Funct. Mater. (2020). https://doi.org/10.1002/adfm.202002578

2. X.B. Cheng, R. Zhang, C.Z. Zhao, Q. Zhang, Toward safe lithium metal anode in rechargeable batteries: a review. Chem.
Rev. 117, 10403-10473 (2017). https://doi.org/10.1021/acs. chemrev.7b00115

3. T. Li, H. Liu, P. Shi, Q. Zhang, Recent progress in carbon/ lithium metal composite anode for safe lithium metal batteries. Rare Met. 37(6), 449-458 (2018). https://doi.org/10.1007/ s12598-018-1049-3

4. X.-Y. Yue, W.-W. Wang, Q.-C. Wang, J.-K. Meng, X.-X. Wang et al., Cuprite-coated $\mathrm{Cu}$ foam skeleton host enabling lateral growth of lithium dendrites for advanced Li metal batteries. Energy Storage Mater. 21, 180-189 (2019). https://doi. org/10.1016/j.ensm.2018.12.007

5. H. Dai, K. Xi, X. Liu, C. Lai, S. Zhang, Cationic surfactantbased electrolyte additives for uniform lithium deposition via lithiophobic repulsion mechanisms. J. Am. Chem. Soc. 140, 17515-17521 (2018). https://doi.org/10.1021/jacs.8b08963

6. J. Ming, Z. Cao, Y. Wu, W. Wahyudi, W. Wang et al., New insight on the role of electrolyte additives in rechargeable lithium ion batteries. ACS Energy Lett. 4, 2613-2622 (2019). https://doi.org/10.1021/acsenergylett.9b01441 